OPEN ACCESS

Edited by:

Saurabh Jamdar,

Manchester Royal Infirmary,

United Kingdom

Reviewed by:

Santhalingam Jegatheeswaran,

Manchester University NHS

Foundation Trust (MFT),

United Kingdom

Minas Baltatzis,

Manchester University NHS

Foundation Trust (MFT),

United Kingdom

*Correspondence:

Xiujun Cai

srrsh_cxj@zju.edu.cn

Ke Chen

chenke68@zju.edu.cn

${ }^{\dagger}$ These authors have contributed equally to this work

Specialty section: This article was submitted to Surgical Oncology,

a section of the journal

Frontiers in Oncology

Received: 12 January 2021 Accepted: 23 March 2021

Published: 07 May 2021

Citation:

Pan Y, Xia S, Cai J, Chen K and Cai X (2021) Efficacy of Laparoscopic Hepatectomy versus Open Surgery for Hepatocellular Carcinoma With Cirrhosis: A Meta-analysis of Case-Matched Studies.

Front. Oncol. 11:652272. doi: 10.3389/fonc.2021.652272

\section{Efficacy of Laparoscopic}

Hepatectomy versus Open Surgery for Hepatocellular Carcinoma With Cirrhosis: A Meta-analysis of Case-Matched Studies

\author{
Yu Pan ${ }^{1,2+}$, Shunjie Xia ${ }^{1,2+}$, Jiaqin $\mathrm{Cai}^{3}, \mathrm{Ke} \mathrm{Chen}^{1,2^{*}}$ and Xiujun Cai ${ }^{1,2^{*}}$ \\ ${ }^{1}$ Department of General Surgery, Sir Run Run Shaw Hospital, School of Medicine, Zhejiang University, Zhejiang, China, \\ ${ }^{2}$ Key Laboratory of Endoscopic Technique Research of Zhejiang Province, Hangzhou, China, ${ }^{3}$ Department of Plastic \\ Surgery, Sir Run Run Shaw Hospital, School of Medicine, Zhejiang University, Zhejiang, China
}

Background: The role of laparoscopic hepatectomy $(\mathrm{LH})$ in hepatocellular carcinoma (HCC) with cirrhosis remains controversial and needs to be further assessed. The present meta-analysis aimed to compare the surgical and oncological outcomes of $\mathrm{LH}$ with those of open hepatectomy $(\mathrm{OH})$ for $\mathrm{HCC}$ with cirrhosis.

Methods: The PubMed, Embase, and Cochrane Library databases were searched for studies comparing LH and OH until Mar 2021. Weighted mean differences (WMDs), odds ratios (ORs), and hazard ratios (HRs) were calculated for continuous, dichotomous, and long-term variables, respectively, with 95\% confidence intervals (Cls). Subgroup analysis was performed according to different resection types: major resection and minor resection. The meta-analysis was performed using the STATA 12.0.

Results: A total of 16 case-matched studies (784 patients in the LH group and 1,191 patients in the $\mathrm{OH}$ group.) were included in this meta-analysis. In terms of primary outcomes, LH was associated with decreased overall complication rate (OR 0.57; 95\% Cl 0.46 to $0.71 ; \mathrm{P}<0.01$ ), major complication rate (OR 0.52; 95\% $\mathrm{Cl} 0.33$ to $0.82 ; \mathrm{P}<0.01$ ), postoperative mortality (OR $0.27 ; 95 \% \mathrm{Cl} 0.11$ to 0.66 ; $\mathrm{P}<0.01$ ), 1 -y overall survival (OS) rate (HR 0.48; 95\% Cl 0.31 to 0.73; $\mathrm{P}<0.01$ ), 2-y OS (HR 0.61; 95\% Cl 0.45 to 0.83; $\mathrm{P}<$ $0.01)$, and 5 -y OS $(0.67 ; 95 \% \mathrm{Cl} 0.53$ to $0.85 ; \mathrm{P}<0.01)$. With respect to secondary outcomes, blood loss (WMD -69.16; 95\% Cl -101.72 to $-36.61 ; \mathrm{P}<0.01$ ), length of hospitalization ( $\mathrm{LOH})(\mathrm{WMD}-2.65 ; 95 \% \mathrm{Cl}-3.41$ to $-1.89 ; \mathrm{P}<0.01$ ), minor complication rate (OR 0.70; 95\% Cl 0.53 to 0.94; $\mathrm{P}=0.02$ ), postoperative liver failure (OR 0.60; 95\% $\mathrm{Cl} 0.38$ to $0.95 ; \mathrm{P}=0.03$ ), and postoperative ascites (OR 0.44; $95 \% \mathrm{Cl} 0.28$ to $0.72 ; \mathrm{P}<$ 0.01) was lower in $\mathrm{LH}$ than in $\mathrm{OH}$. No significant differences in operation time $(\mathrm{P}=0.07)$, transfusion rate $(P=0.05), 1-, 2-$, and 5-year DFS rate (1-year, $P=0.08$; 2-year, $P=0.08$; 5 -year, $\mathrm{P}=0.23$ ) were noted between $\mathrm{LH}$ and $\mathrm{OH}$. Subgroup analysis based on minor resection revealed that $\mathrm{LH}$ had similar favored outcomes in comparison with those in the overall pooled analysis. However, $\mathrm{LH}$ had a longer operation time than $\mathrm{OH}$ in the setting of major resection $(P<0.01)$. 


\begin{abstract}
Conclusion: LH is technically feasible and safe for selected HCC patients with cirrhosis. LH can achieve favored short-term and long-term oncological outcomes in minor liver resection. Laparoscopic major hepatectomy (LMH) seems to offer some advantages over the open approach; however concerns about surgical and oncological safety remain. More evidence on $\mathrm{LMH}$ is warranted before expanding its indication to patients with cirrhosis.
\end{abstract}

Keywords: laparoscopic hepatectomy, hepatocellular carcinoma, cirrhosis, prognosis, meta-analysis

\section{INTRODUCTION}

Hepatocellular carcinoma (HCC) is the most common primary cancer of the liver and one of the leading causes of cancer-related deaths worldwide $(1,2)$. Hepatectomy is the commonly used curative treatment strategy for very early- and early-stage HCC patients with preserved liver function. In the early 1990s, with the inception of laparoscopic techniques, initial reports on laparoscopic hepatectomy (LH) were published $(3,4)$. Since then, the laparoscopic approach has been increasingly accepted in the field of liver surgery. Laparoscopic techniques have been shown to expedite recovery, improve postoperative pain, and result in better cosmesis than the open approach. In the statement of the First International Consensus Conference for Laparoscopic Liver Resection, laparoscopic left lateral segmentectomy was identified as the gold standard approach (5). In 2014, the Second International Consensus Conference for Laparoscopic Liver Resection recommended laparoscopic minor hepatectomy as the standard surgical practice (6).

Most patients with HCC commonly have chronic hepatitis and cirrhosis making liver resection technically demanding. Liver resection is a challenging procedure in the setting of cirrhosis owing to elevated portal pressure and impaired coagulation function in patients with this condition. A retrospective study by Neeff et al. reported that the severity of cirrhosis was correlated with perioperative mortality after hepatectomy (7). The development of devices and techniques for hemostasis has allowed bleeding control in LH. Several efforts have been made to promote the adoption of LH in the treatment of HCC with cirrhosis (8-11). Given the advantages of laparoscopic surgery in terms of minimal invasiveness, $\mathrm{LH}$ is expected to be more beneficial for HCC patients with cirrhosis. Several meta-analyses have reported that patients with cirrhosis undergoing LH experienced less blood loss, fewer postoperative complications, and shorter hospital stays than those undergoing open resection $(12,13)$. Most studies included in these metaanalyses were retrospective and limited to laparoscopic minor resection. Since then, one randomized clinical trial (RCT) and several case-matched studies focusing on HCC with cirrhosis have reported the favored surgical outcomes of LH (14-16). Furthermore, major liver resection is an important curative modality for HCC. Recently, laparoscopic major hepatectomy (LMH) for selected patients with cirrhosis has been reported by several experienced surgeons in a few medical centers $(17,18)$. Hence, in this study, we aimed to compare the surgical and oncological outcomes of $\mathrm{LH}$ with those of open hepatectomy $(\mathrm{OH})$ for HCC with cirrhosis by collecting high-quality case-matched studies.

\section{METHODS}

\section{Search Strategy}

This systematic review was conducted in accordance with the Preferred Reporting Items for Systematic Reviews and MetaAnalyses (PRISMA) guidelines (19). Electronic databases including PubMed, Embase, and Cochrane Library were searched. The search strategy for Pubmed was as follows: ((((("Minimally Invasive Surgical Procedures"[Mesh]) OR "Laparoscopy"[Mesh])) AND "Liver Cirrhosis"[Mesh]) AND "Liver Neoplasms"[Mesh]) and similar strategy was performed in other databases. The references of the retrieved results were also manually reviewed to obtain more related articles as possible. The final search was conducted in Mar 2021. No institutional review board approval or patient written consent was necessary because only published data were used.

\section{Study Selection}

Case-matched studies written in English and comparing the outcomes of $\mathrm{OH} v s \mathrm{LH}$ for HCC in patients with cirrhosis were considered for inclusion. The exclusion criteria were as follows: (i). reviews, editorials, case reports, abstracts, or letters; (ii). studies including patients without cirrhosis or those with unproven cirrhosis; (iii). studies including patients who underwent robotic or hybrid procedures; (iv). overlapped studies; (v). studies that did not report at least three of the primary outcomes.

\section{Data Extraction}

After the initial screening, full-text versions of the selected articles were obtained. Two reviewers (SX and $\mathrm{KC}$ ), as well as an independent third reviewer (YP) in cases in which consensus could not be reached, individually assessed each article and rejected those that failed to meet the inclusion criteria. The following items were extracted: year of publication, study design, sample size, country of study, patient characteristics, and outcome measures. The primary outcomes were overall complication rate, major complication rate, postoperative mortality, overall survival (OS) rate, and disease-free survival (DFS) rate. The secondary outcomes were operation time, blood loss, transfusion rate, length of hospitalization ( $\mathrm{LOH})$, minor complication rate, postoperative ascites, and postoperative liver failure (POLF). The NewcastleOttawa scale (NOS) was used to evaluate the quality of observational studies (http://www.ohri.ca/programs/clinical_ epidemiology/oxford.asp). The NOS scores were $\geq 7$, were considered of high quality. According to previous studies, minor resection was defined as hepatectomy of fewer than three sections 
and major resection was defined as hepatectomy of more than three sections (20-22). Clavien-Dindo classification was used to grade postoperative complications and a major complication was defined as Clavien-Dindo $\geq 3$; otherwise, the complication was defined as minor (23).

\section{Statistical Analysis}

Dichotomous variables were evaluated using odds ratios (ORs) with 95\% confidence intervals (95\% CIs), and continuous variables were analyzed using the weighted mean differences (WMDs) with $95 \%$ CIs. The hazard ratio (HR) was used as a summary statistic for longterm outcomes (survival analysis), as described by Tierney et al. (24). Medians were converted to means using the formula described by Hozo et al. (25). According to the Higgins $\mathrm{I}^{2}$ statistic, heterogeneities $<25,25$ to 50 , and $>50 \%$ were defined as low, moderate, and high, respectively (26). A fixed-effects model was used for studies with low or moderate statistical heterogeneity (27), whereas a random-effects model was used for studies with high statistical heterogeneity (28). Subgroup analysis was performed according to different resection types: major resection and minor resection. Funnel plots were used to estimate the potential publication bias. $\mathrm{P}<0.05$ was considered statistically significant. The meta-analysis was performed using the STATA 12.0 .

\section{RESULTS}

\section{Study Characteristics}

This meta-analysis was registered to PROSPERO (https://www.crd. york.ac.uk/prospero/) with an ID of CRD42020161775. The search strategy initially retrieved 501 records. After the exclusion of irrelevant studies by screening the abstracts, the full texts of 28 potentially relevant articles were obtained for assessment. Twelve studies were excluded due to overlapping data, inclusion of patients without cirrhosis, unavailable statistical data, non-comparative studies, non-case matched studies (8, 9, 29-38). Sixteen studies were eventually included $(15-18,39-50)$. The PRISMA flowchart of the literature review is presented in Figure 1.

The characteristics of the included studies are summarized in Table 1. A total of 1,975 patients from both Eastern and Western countries were pooled in this meta-analysis: 784 patients in the $\mathrm{LH}$ group and 1,191 patients in the $\mathrm{OH}$ group. To balance the basic characteristics, the propensity score matching method was used in 12 out of 16 retrospective studies, whereas the casematched method was used in the others. Detail of matched characteristics was summarized in Supplementary Table 1. Nine studies focused on minor liver resection, and five studies reported outcomes limited to patients who underwent major liver resection. Ten studies reported the conversion rate of $\mathrm{LH}$,

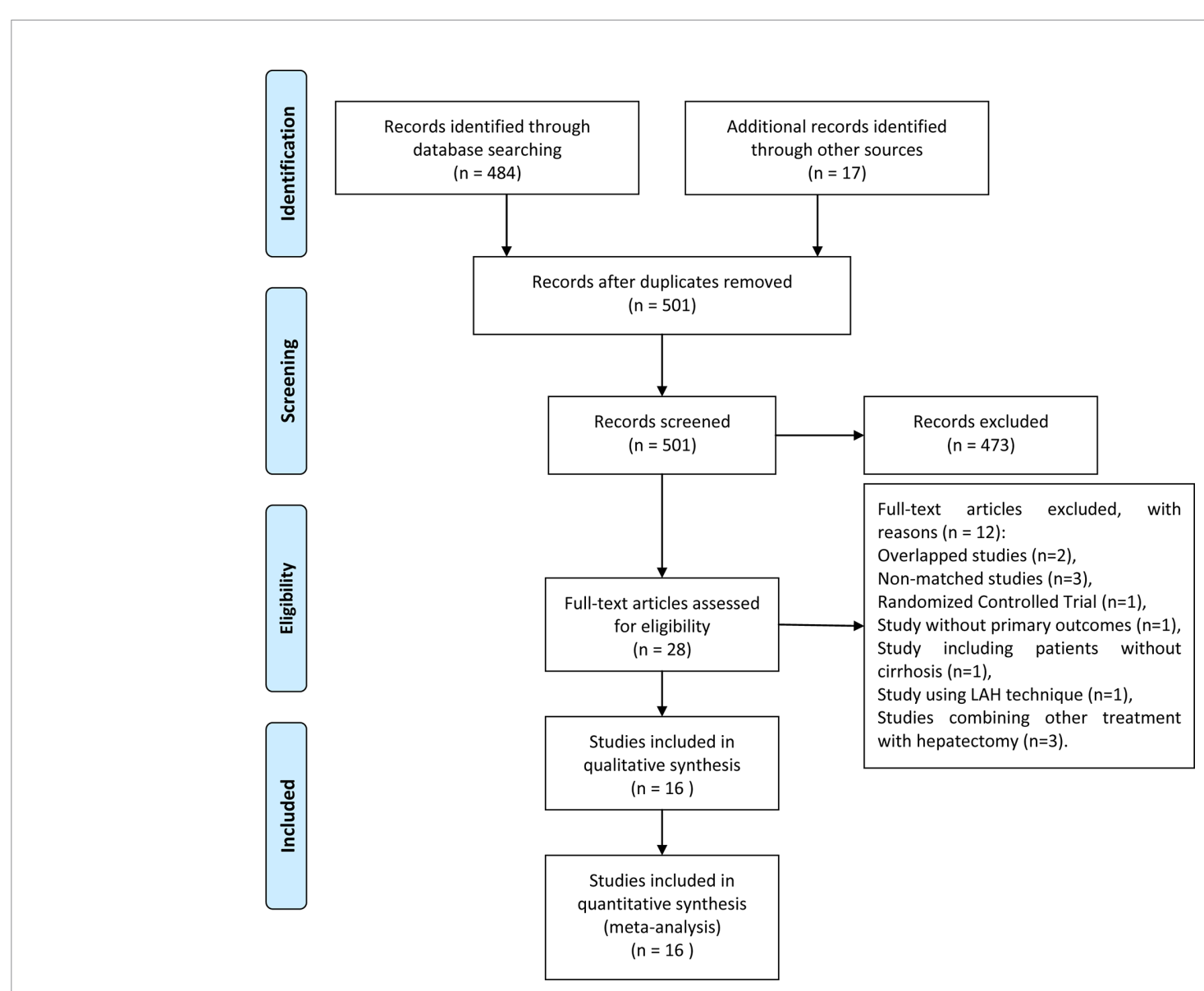

FIGURE 1 | Flow chart of the studies included in the meta-analysis. 
TABLE 1 | The basic characteristics of included studies.

\begin{tabular}{|c|c|c|c|c|c|c|c|c|c|c|c|c|}
\hline study & year & Country & Study design & $\begin{array}{l}\text { sample size } \\
\text { (LH/OH) }\end{array}$ & $\begin{array}{c}\text { Mean age } \\
\text { (LH/OH) }\end{array}$ & $\begin{array}{c}\text { Gender (M/F) } \\
\text { (LH/OH) }\end{array}$ & $\begin{array}{c}\text { Childs-Pugh A:B ratio } \\
\text { (LH/OH) }\end{array}$ & $\begin{array}{l}\text { tumor size } \\
\text { (LH/OH) }\end{array}$ & $\begin{array}{l}\text { tumor pattern } \\
\text { (LH/OH) }\end{array}$ & $\begin{array}{l}\text { conversion } \\
\text { rate }\end{array}$ & resection type & $\begin{array}{l}\text { Matched } \\
\text { method }\end{array}$ \\
\hline Belli et al. & 2007 & Italy & $\mathrm{R}$ & 23 vs 23 & 59.5 vs 62.4 & $13 / 10$ vs $14 / 9$ & $23 / 0$ vs $23 / 0$ & 3.1 vs 3.2 & NA & 0 & minor & M \\
\hline Truant et al. & 2011 & France & $\mathrm{R}$ & 36 vs 53 & 60.6 vs 63.3 & $31 / 5$ vs $47 / 6$ & $36 / 0$ vs $53 / 0$ & 2.9 vs 3.1 & $34 / 2$ vs $44 / 9$ & NA & minor & M \\
\hline Memeo et al. & 2014 & France & $\mathrm{R}$ & 45 vs 45 & 62 vs 60 & $35 / 10$ vs $37 / 8$ & $44 / 1$ vs $43 / 2$ & 3.2 vs 3.7 & NA & 0 & minor & M \\
\hline Komatsu et al. & 2016 & Japan & $\mathrm{R}$ & 38 vs 38 & 61.5 vs 61.7 & $34 / 4$ vs $33 / 5$ & $38 / 0$ vs 38/0 & 4.75 vs 8.5 & $19 / 19$ vs $22 / 16$ & $34.21 \%$ & major & M \\
\hline Cheung et al. & 2016 & China & $\mathrm{R}$ & 110 vs 330 & 60 vs 61 & $\begin{array}{c}80 / 30 \text { vs } 258 / \\
72\end{array}$ & $110 / 0$ vs $330 / 0$ & 2.6 vs 2.85 & $\begin{array}{c}100 / 10 \text { vs 292/ } \\
38\end{array}$ & $5.5 \%$ & minor & PSM \\
\hline Jiang et al. & 2016 & China & $\mathrm{R}$ & 59 vs 59 & 51 vs 50 & $42 / 17$ vs $38 / 21$ & $59 / 0$ vs $59 / 0$ & 3 vs 3 & $59 / 0$ vs $59 / 0$ & $5.1 \%$ & minor & PSM \\
\hline Yoon et al. & 2017 & Korea & $\mathrm{R}$ & 33 vs 33 & $\begin{array}{c}56.03 \text { vs } \\
57.33\end{array}$ & $23 / 10$ vs $26 / 7$ & $33 / 0$ vs $33 / 0$ & $\begin{array}{l}3.31 \mathrm{vs} \\
2.96\end{array}$ & NA & NA & major & PSM \\
\hline Xu et al. & 2018 & China & $\mathrm{R}$ & 32 vs 32 & 53.5 vs 52 & $28 / 4$ vs $28 / 4$ & $32 / 0$ vs 32/0 & 4 vs 6.2 & $29 / 3$ vs $29 / 3$ & NA & major & PSM \\
\hline Kim et al. & 2018 & Korea & $\mathrm{R}$ & 18 vs 36 & 55.7 vs 54.6 & $13 / 5$ vs $22 / 14$ & $18 / 0$ vs $36 / 0$ & 2.9 vs 3.66 & $18 / 0$ vs $36 / 0$ & 0 & minor & PSM \\
\hline Sandro et al. & 2018 & Italy & $\mathrm{R}$ & 75 vs 75 & 68.6 vs 67.1 & $33 / 42$ vs $24 / 51$ & $65 / 10$ vs $63 / 12$ & 2.5 vs 2.5 & $66 / 9$ vs $65 / 10$ & $7.6 \%$ & minor & PSM \\
\hline $\begin{array}{l}\text { Delvecchio } \\
\text { et al. }\end{array}$ & 2020 & & $\mathrm{RM}$ & 38 vs 84 & 75 vs 74.3 & $29 / 9$ vs $61 / 23$ & $37 / 1$ vs $82 / 2$ & 4 vs 7 & $33 / 5$ vs $68 / 18$ & NA & major & PSM \\
\hline Cheung et al. & 2020 & China & $\mathrm{R}$ & 24 vs 96 & 63 vs 62 & $20 / 4$ vs $81 / 15$ & $24 / 0$ vs $96 / 0$ & 4.5 vs 4.8 & $18 / 6$ vs $75 / 21$ & NA & major & PSM \\
\hline Hobeika et al. & 2020 & France & $\mathrm{R}$ & 124 vs 124 & 63 vs 63 & $\begin{array}{c}98 / 26 \text { vs } 101 / \\
13\end{array}$ & NA & NA & NA & $16.8 \%$ & minor & PSM \\
\hline $\begin{array}{l}\text { Yamamoto } \\
\text { et al. }\end{array}$ & 2020 & Japan & $\mathrm{R}$ & 58 vs 58 & 71 vs 72 & $39 / 19$ vs $30 / 28$ & $45 / 13$ vs $45 / 13$ & 1.7 vs 1.6 & NA & NA & minor & PSM \\
\hline Inoue et al. & 2020 & Japan & $\mathrm{R}$ & 28 vs 28 & 73 vs 72 & $19 / 9$ vs $18 / 10$ & $28 / 0$ vs $27 / 1$ & 2.4 vs 2.4 & NA & $12.70 \%$ & NA & PSM \\
\hline Fu et al. & 2021 & China & $\mathrm{R}$ & 43 vs 77 & 52 vs 56 & $33 / 10$ vs $59 / 18$ & $43 / 0$ vs $70 / 0$ & 2.5 vs 2.5 & NA & $2.0 \%$ & NA & PSM \\
\hline
\end{tabular}

LH laparoscopic hepatectomy, OH open hepatectomy, M male, F female, NA not available, R retrospective, RM retrospective multicenter, PSM propensity score-matched. 
TABLE 2 | The qualities of included studies evaluated using the Newcastle-Ottawa Quality Assessment Scale.

\begin{tabular}{|c|c|c|c|c|}
\hline \multirow[t]{2}{*}{ Study } & Selection & Comparability & Outcomes & Total \\
\hline & $\begin{array}{l}\text { 1. Representativeness of exposed cohort } \\
\text { 2. Selection of nonexposed cohort } \\
\text { 3. Ascertainment of exposure } \\
\text { 4. Outcome not present at the start of the study }\end{array}$ & & $\begin{array}{l}\text { 1. Assessment of outcomes } \\
\text { 2. Length of follow-up } \\
\text { 3. Adequacy of follow-up }\end{array}$ & \\
\hline Belli et al. & 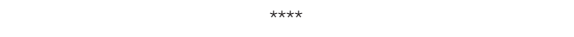 & ** & $\star \star *$ & 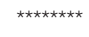 \\
\hline Truant et al. & 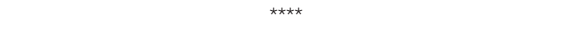 & ** & $\star \star \star ~$ & 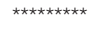 \\
\hline Memeo et al. & 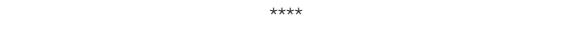 & $\star \star$ & $\star \star \star \star$ & 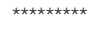 \\
\hline Cheung et al. & 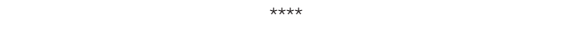 & ** & $\star \star \star$ & 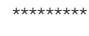 \\
\hline Jiang et al. & 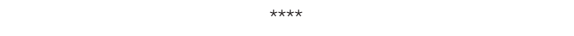 & ** & * & 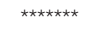 \\
\hline Komatsu et al. & 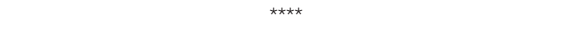 & ** & ** & 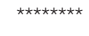 \\
\hline Yoon et al. & 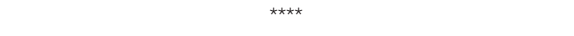 & ** & ** & 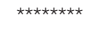 \\
\hline Sandro et al. & 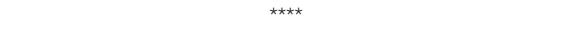 & ** & $\star \star$ & 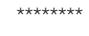 \\
\hline Xu et al. & 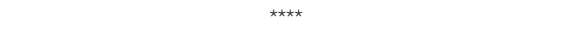 & $\star \star$ & $\star \star$ & 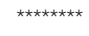 \\
\hline Kim et al. & 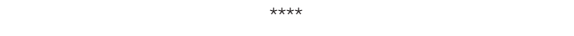 & ** & $\star \star$ & 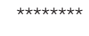 \\
\hline Delvecchio et al. & 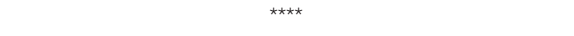 & $\star \star$ & $\star \star \star \star$ & 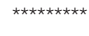 \\
\hline Cheung et al. & 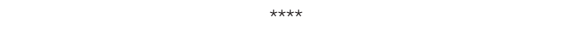 & ** & 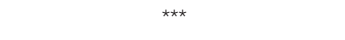 & 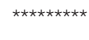 \\
\hline Hobeika et al. & 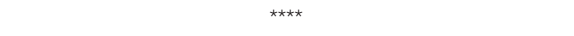 & ** & * & 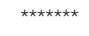 \\
\hline Yamamoto et al. & 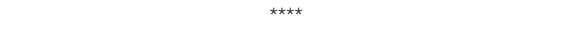 & ** & $\star \star \star \star$ & 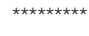 \\
\hline Inoue et al. & 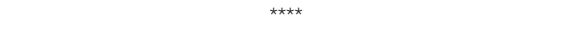 & ** & * & 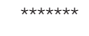 \\
\hline Fu et al. & 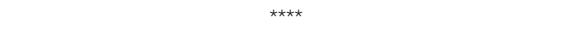 & $\star \star$ & * & 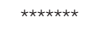 \\
\hline
\end{tabular}

which ranged from 0 to $34.21 \%$. Surgical techniques including inflow occlusion method, parenchymal transection technique, and hemostasis method, were summarized in Supplementary Table 2. All studies were considered to be of adequate quality for the meta-analysis, as presented in Table 2 .

\section{Intraoperative Outcomes}

All 16 pooled studies reported the operation time. Compared with the $\mathrm{OH}$ group, the $\mathrm{LH}$ group achieved a comparable operation time (WMD 19.33, 95\% CI -1.67 to 40.34 ; P $=0.07$; Figure 2A). According to 15 studies reporting intraoperative blood loss, our meta-analysis found blood loss was less in the LH than that in the $\mathrm{OH}$ groups (WMD -69.16; 95\% CI -101.72 to $-36.61 ; \mathrm{P}<0.01$; Figure 2B). Similarly the occurrence of transfusion in $\mathrm{LH}$ was less than that in $\mathrm{OH}(\mathrm{OR} 0.63 ; 95 \% \mathrm{CI}$ 0.40 to $1.00 ; \mathrm{P}=0.05$; Figure $2 \mathrm{C}$ ).

\section{Postoperative Outcomes}

A shorter LOH was observed in LH (WMD -2.65; 95\% CI -3.41 to $-1.89 ; \mathrm{P}<0.01$; Figure $3 \mathrm{~A}$ ). Postoperative complications were recorded in fifteen studies. The LH group had a decreased risk of overall postoperative complications (OR 0.57 ; 95\% CI 0.46 to $0.71 ; \mathrm{P}<0.01$; Figure 3B). Moreover, 15 studies reported postoperative mortalities. On the basis of these data, $\mathrm{LH}$ had a lower mortality rate (OR $0.27 ; 95 \%$ CI 0.11 to 0.66 ; $\mathrm{P}<0.01$; Figure $3 \mathrm{C}$ ). To clarify the influence of $\mathrm{LH}$ on postoperative complications, we classified postoperative complications into minor complications and major complications.

With respect to the overall postoperative complications, the $\mathrm{LH}$ group had more favorable minor complication rate (OR 0.70; $95 \%$ CI 0.53 to $0.94 ; \mathrm{P}=0.02$; Figure $4 \mathrm{~A}$ ) and major complication rate (OR 0.52; 95\% CI 0.33 to 0.82; $\mathrm{P}<0.01$; Figure 4B) than $\mathrm{OH}$. We also evaluated some detailed complications specifically associated with liver resection in patients with cirrhosis, including POLF and ascites. The LH group had less POLF (OR 0.60; 95\% CI 0.38 to 0.95; P = 0.03; Figure 4C) and ascites (OR 0.44; 95\% CI 0.28 to $0.72 ; \mathrm{P}<0.01$; Figure 4D) than the $\mathrm{OH}$ group.

\section{Long-Term Outcomes}

Twelve studies reported the long-term outcomes including OS and DFS rates. The data showed that $\mathrm{LH}$ had more favorable 1-, 2-, and 5-year OS rate (1-year: HR 0.48; 95\% CI 0.31 to 0.73 ; $\mathrm{P}<0.01$; Figure 5A; 2-year: HR 0.61; 95\% CI 0.45 to 0.83 ; P < 0.01; Figure 5C; 5-year: HR 0.67; 95\% CI 0.53 to 0.85; P < 0.01; Figure 5E) than $\mathrm{OH}$. As for the DFS rate, LH had comparable outcomes to $\mathrm{OH}$ in terms of 1-, 2-, and 5-year DFS rates (1-year: HR 0.73; 95\% CI 0.52 to $1.04 ; \mathrm{P}=$ 0.08 ; Figure 5B; 2-year: HR 0.86; $95 \%$ CI 0.73 to $1.02 ; \mathrm{P}=0.08$; Figure 5D; 5-year: HR 0.90; $95 \%$ CI 0.75 to 1.07 ; $\mathrm{P}=0.23$; Figure 5F).

\section{Subgroup Analysis}

Given that the included studies enrolled patients who underwent different extents of liver resection, subgroup analysis was conducted according to the resection extent (minor or major resection), as shown in Table 3. In accordance with the overall analysis, LH was associated with less blood loss, shorter $\mathrm{LOH}$, fewer postoperative complications and mortalities, better 1-year, 2-year, and 5-year OS rate in minor resection subgroup analysis. Notably, in the major resection subgroup analysis, the LH group had a longer operation time, shorter $\mathrm{LOH}$, and fewer postoperative complications than the $\mathrm{OH}$ group. Moreover, there was no difference in the OS and DFS rates between the $\mathrm{LH}$ and $\mathrm{OH}$ groups in the major resection subgroup analysis.

\section{Sensitivity Analysis and Publication Bias}

Sensitivity analyses were conducted by excluding the highestweighted study in each pooled analysis. These exclusions did not alter the results of cumulative analyses. A funnel plot based on overall postoperative complications was performed to assess 
A

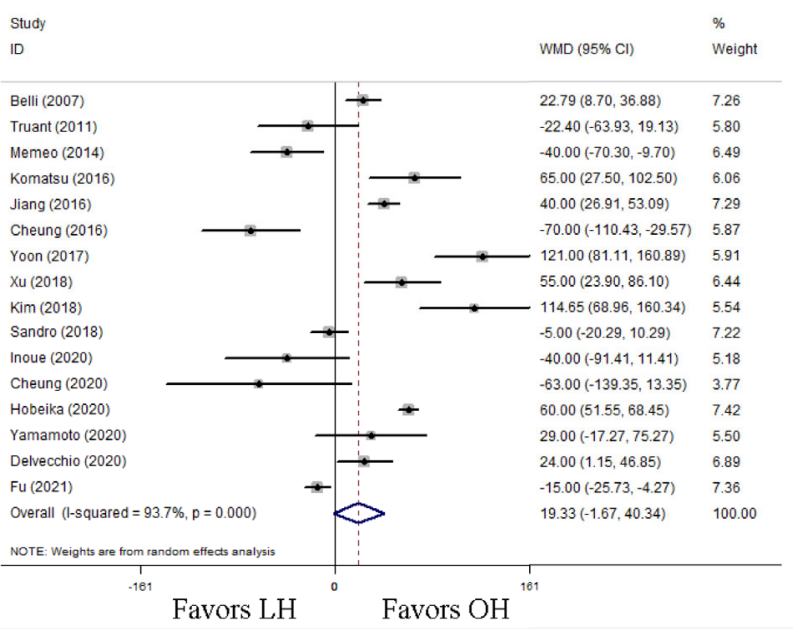

B

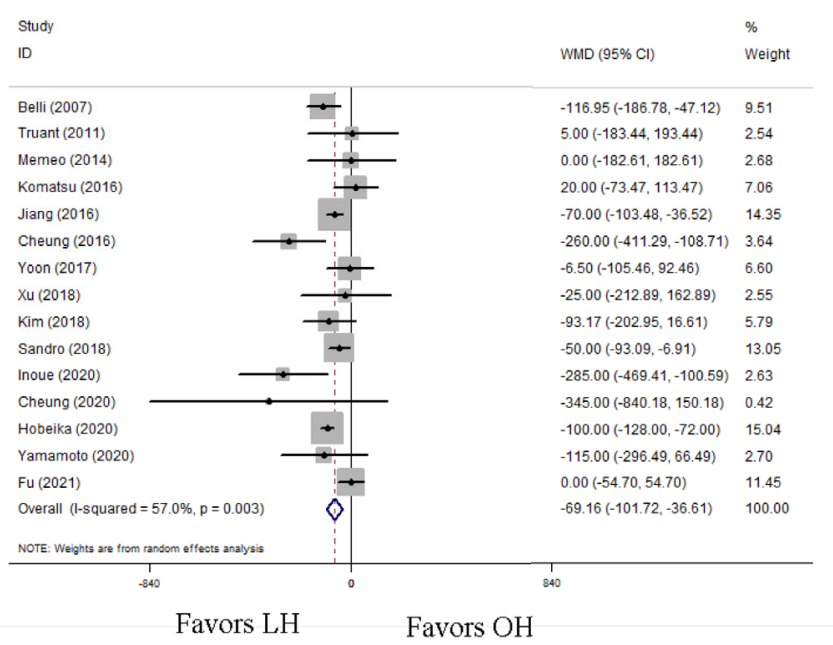

C

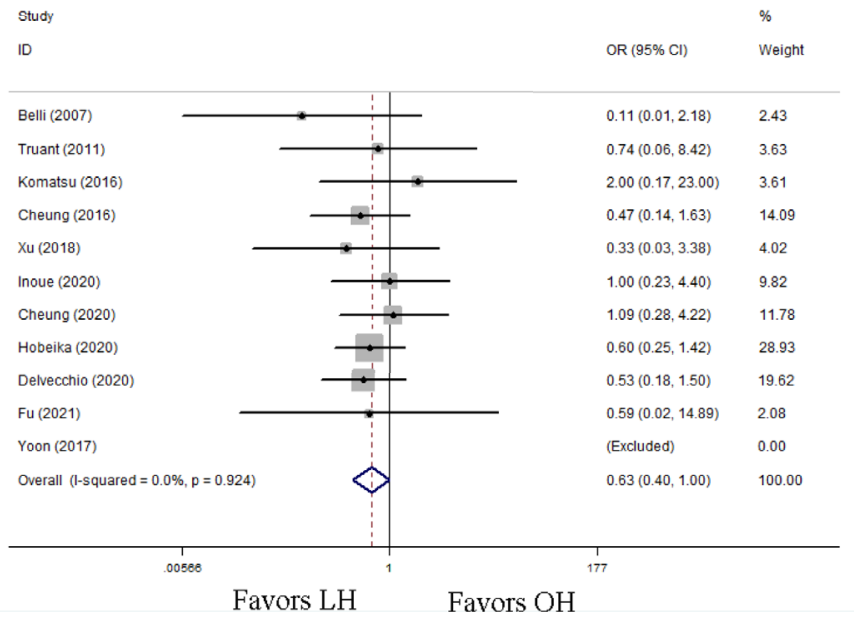

FIGURE 2 | Forest plots of intraoperative outcomes, (A) operation time, (B) blood loss, (C) transfusion rate. 
A

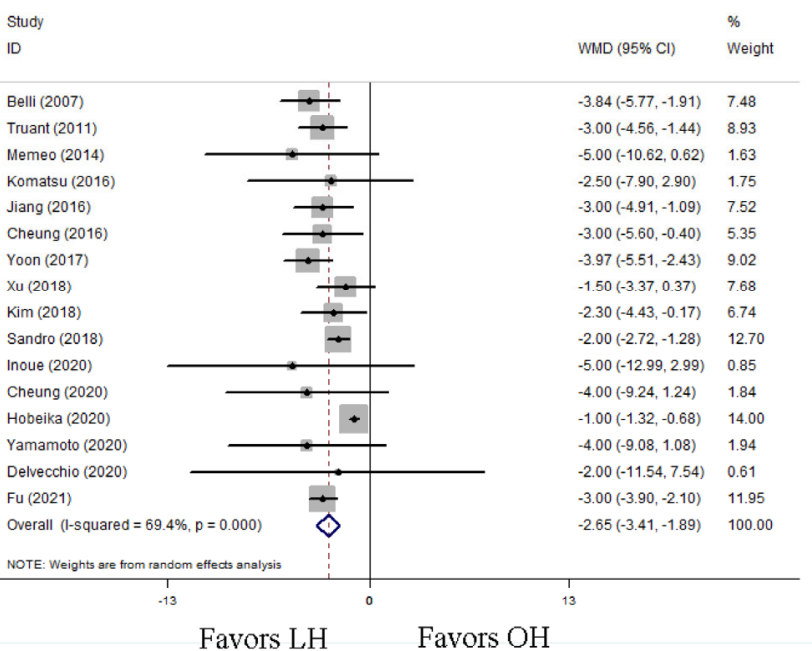

B

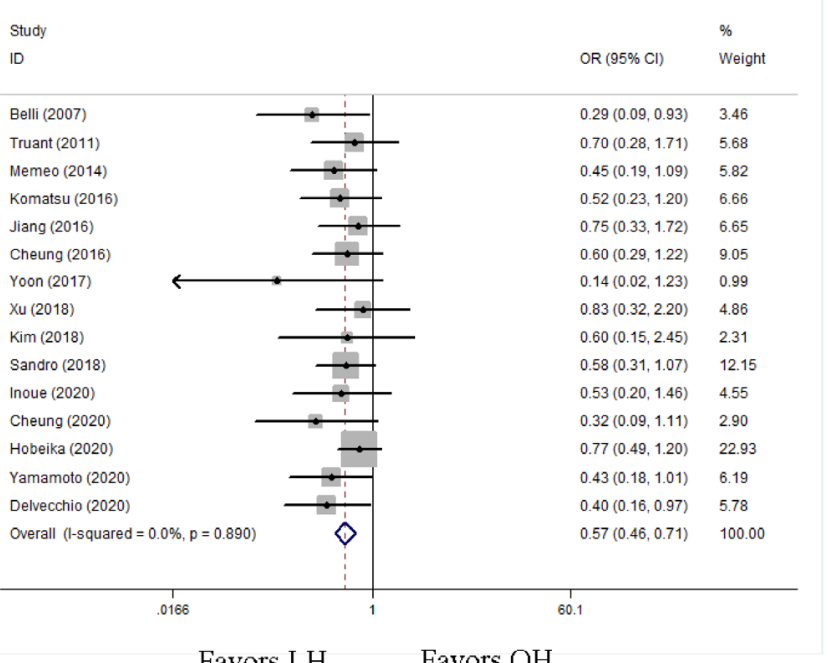

C

Belli (2007)

Truant (2011)

Memeo (2014)

Cheung (2016)

$\mathrm{Xu}(2018)$

Sandro (2018)

Inoue (2020)

Cheung (2020)

Hobeika (2020)

Delvecchio (2020)

Komatsu (2016)

Jiang (2016)

Yoon (2017)

Kim (2018)

Overall (1-squared $=0.0 \%, p=0.974$ )

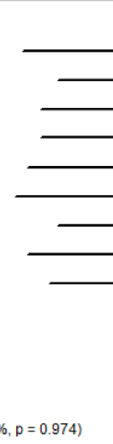

.00700

Favors $\mathrm{OH}$

Favors LH

$\%$

$3.00(0.12,77.47) \quad 7.92$

$0.16(0.01,3.12) \quad 9.61$

$0.17(0.02,1.44) \quad 18.00$

$0.23(0.01,4.12) \quad 10.07$

$0.33(0.01,8.49) \quad 7.99$

$0.20(0.01,4.24) \quad 8.98$

$0.14(0.01,2.89) \quad 9.25$

$0.36(0.02,6.70) \quad 9.76$

$0.20(0.01,4.21) \quad 9.02$

$0.31(0.02,6.22) \quad 9.38$

(Excluded) $\quad 0.00$

(Excluded) $\quad 0.00$

(Excluded) $\quad 0.00$

(Excluded) $\quad 0.00$

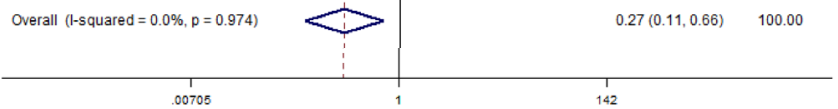

Favors LH Favors OH

FIGURE 3 | Forest plots of postoperative outcomes, (A) length of postoperative hospitalization, (B) overall postoperative complication, (C) postoperative mortality. 
A

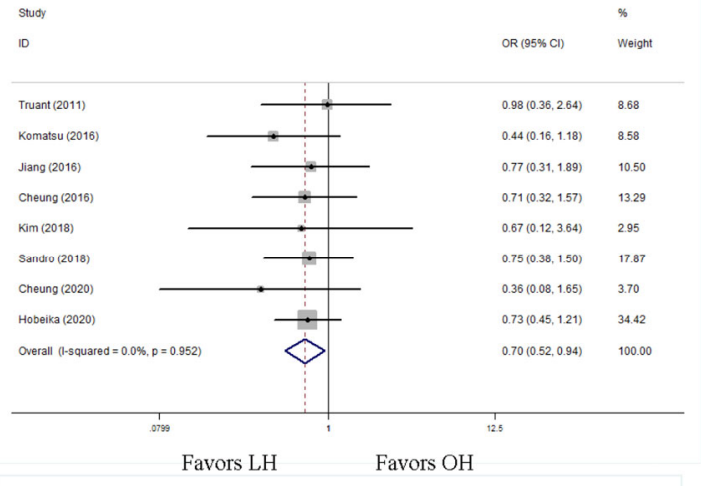

B

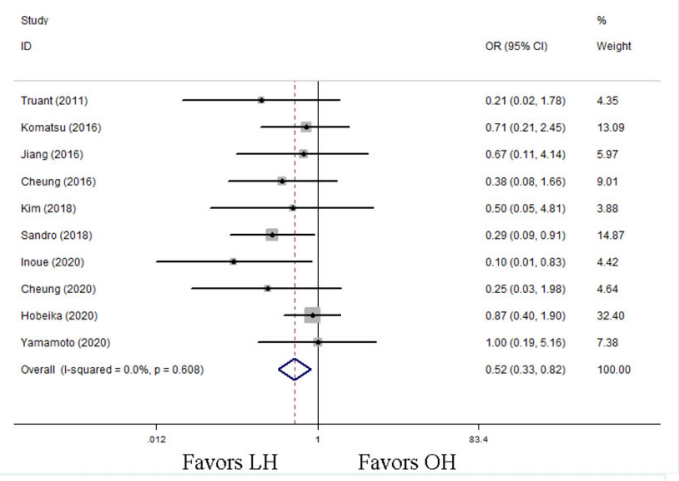

C

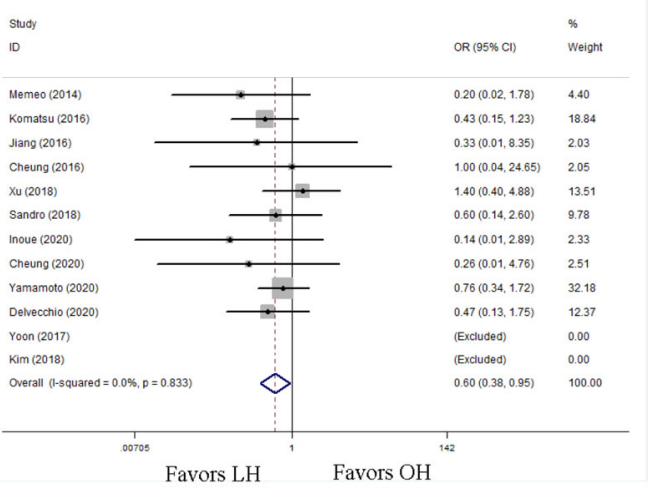

D

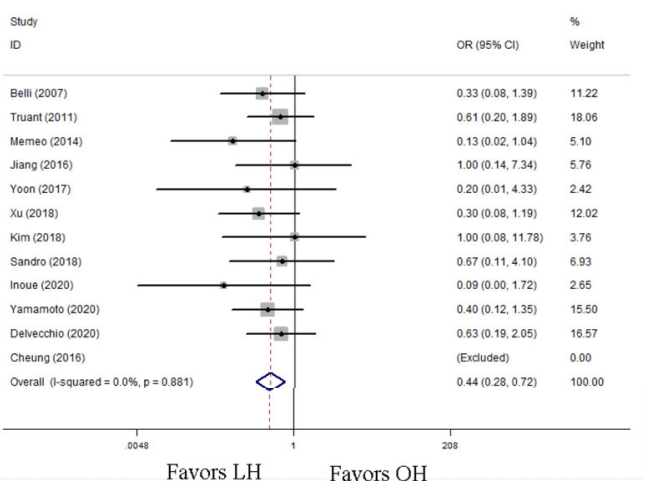

FIGURE 4 | Forest plots of postoperative complication in detail, (A) minor complication, (B) major complication, (C) postoperative liver failure, (D) ascites. publication bias. No significant publication bias was detected by visual inspection of the funnel plot, in which the pooled studies were almost symmetrical and none of them were outside the $95 \%$ CI (Figure 6).

\section{DISCUSSION}

$\mathrm{OH}$ is a well-established curative treatment for HCC. However, patients with poor liver functional reserve, such as those with cirrhosis, are at higher risk of undergoing $\mathrm{OH}$ with a large surgical incision, wide extent of resection, and relatively large amount of blood loss. $\mathrm{LH}$ is emerging as a promising alternative approach for HCC patients with cirrhosis. Several previous meta-analyses have evaluated the advantages and disadvantages of LH (Table 4). Studies by Twaij et al. and Chen et al. identified significantly decreased overall postoperative complications, mortality, blood loss, and $\mathrm{LOH}$ in the LH group $(12,13)$. Goh et al. reported that LH was associated with better oncological outcomes (51). However, most studies included in those meta-analyses were retrospective studies with small sample sizes, which are prone to biases. Recently, several high-quality articles comparing $\mathrm{LH}$ and $\mathrm{OH}$ for HCC with cirrhosis have been published (14-18). To minimize the selection bias, this systematic review and meta-analysis pooled 16 case-matched retrospective studies. Comparisons were made between $\mathrm{LH}$ and $\mathrm{OH}$ for HCC in patients with cirrhosis, along with subgroup analysis according to different surgical extents.

Consistent with previous studies, the main findings obtained from our meta-analysis showed that patients who underwent $\mathrm{LH}$ presented notable oncological advantages in terms of 1-, 2-, and 5year OS and 1-year DFS. In addition, our meta-analysis showed that LH was associated with lower postoperative morbidity, lower mortality, less blood loss, and shorter $\mathrm{LOH}$ than $\mathrm{OH}$.

The primary concern with $\mathrm{LH}$ was bleeding control during transection in the setting of cirrhosis. The impact of cirrhosis on portal vein pressure and coagulation, and the movement restriction in laparoscopic surgery, make bleeding control challenging and increase the conversion risk. Truant et al. reported that uncontrolled bleeding accounted for $57.1 \%$ (4/7) of total conversion (42). Similarly, Sandro et al. also reported that one-third (2/7) of patients underwent conversion because of bleeding (15). With the accumulation of surgical experience, bleeding control during transection has been established by using the Pringle maneuver, compression with or without hemostatic material, clipping, suturing, temporary clamp for vessels, and various energy devices. Simultaneously, decreased intraoperative blood loss has been achieved with the application of appropriate pneumoperitoneum pressure, which reduces venous bleeding, and a magnified operating view, which allows meticulous manipulation. In this meta-analysis, the blood loss in the LH group was less than that in the $\mathrm{OH}$ group, as reported in previous studies. The considerable decrease in blood loss with the LH procedure means a decreased risk of transfusion. Accordingly, a lower transfusion rate in the LH group was observed in the present study. 


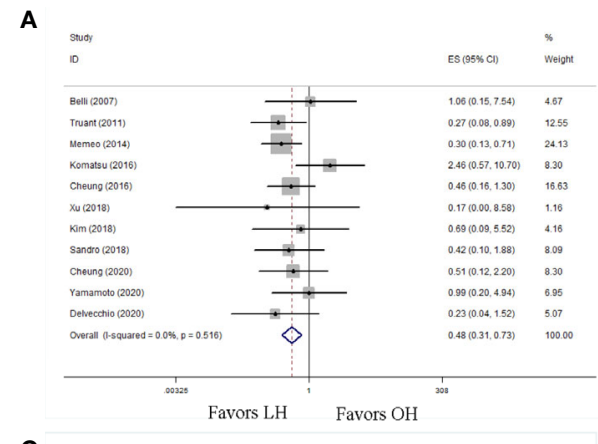

C

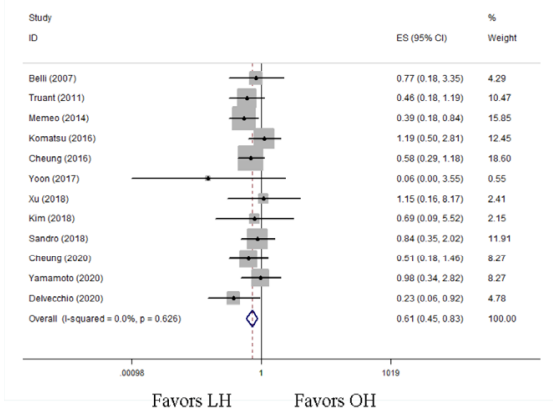

E

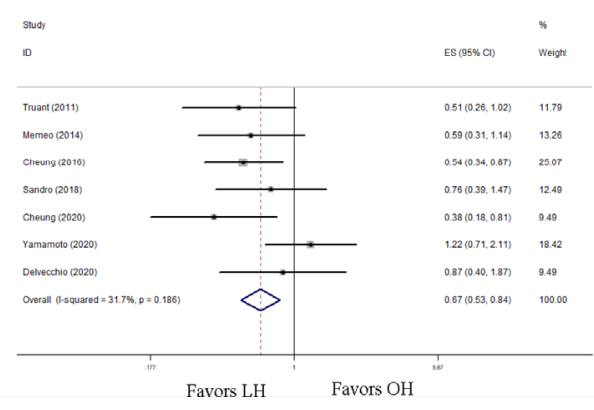

B

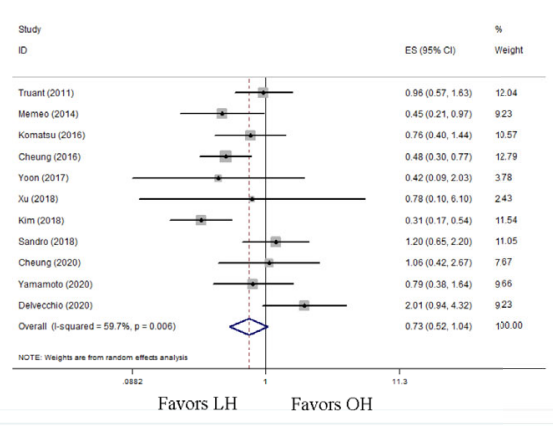

D

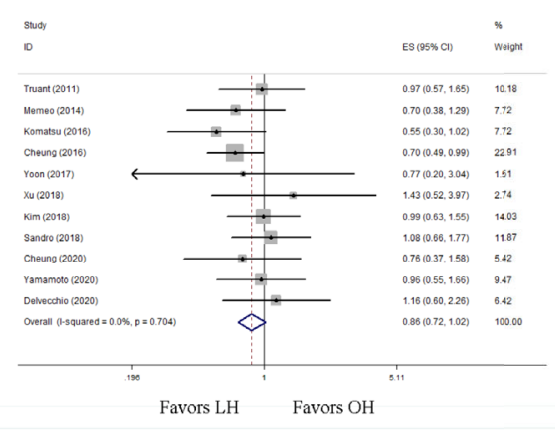

$\mathbf{F}$

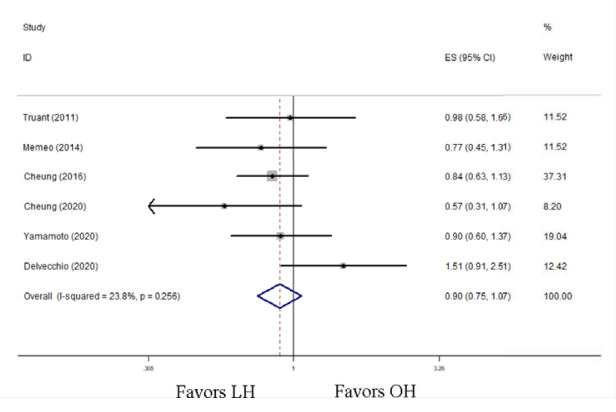

FIGURE 5 | Forest plots of long-term outcomes, (A) 1-y overall survival rate, (B) 1-y disease-free survival rate, (C) 2-y overall survival rate, (D) 2-y disease-free survival rate, (E) 5-y overall survival rate, (F) 5-y disease-free survival rate.

Decreased blood loss, avoidance of large incisions and meticulous manipulation alleviate the surgical trauma. The minimally invasive approach reduces the risk of acute or delayed systematic adverse events and subsequent postoperative morbidity and mortality. The overall complication rate of $\mathrm{LH}$ was approximately $22.8 \%(169 / 741)$, which was significantly lower than that of $\mathrm{OH}(34.9 \%, 389 / 1,114)$. Recently, Goh et al. examined 400 cases of $\mathrm{LH}$ and reported a postoperative morbidity of $18.8 \%$, which is equivalent to the present study (52). A similar result was observed in that $\mathrm{OH}$ had a nearly four-fold risk of postoperative death in comparison with $\mathrm{LH}(\mathrm{OR}=0.28)$.

Hepatectomy can lead to refractory ascites in patients with cirrhosis, which can be fatal. By preserving the integrity of the abdominal wall and reducing surgery-induced injury to the area surrounding the liver, disruption of collateral blood and lymphatic flow is minimized in the laparoscopic approach. Further analysis of postoperative complications revealed that the $\mathrm{LH}$ group had less postoperative ascites. The $\mathrm{LH}$ group had fewer major and minor complications as than the $\mathrm{OH}$ group. Furthermore, in the setting of LH, minor complications were predominant, accounting for $75.8 \%(91 / 120)$ of the overall complications, which was significantly higher than that in $\mathrm{OH}(68.2 \%, 176 / 258)$. Therefore, it can be deduced that LH is technically safe and tends to have fewer and milder complications.

Reduced surgical trauma, fewer postoperative events, and enhanced recovery resulted in shorter LOH and lower medical costs. More importantly, the present study demonstrated that patients undergoing LH had better oncological outcomes, including 1-, 2-, 5-year OS and 1-year DFS. Although no statistical difference was found in 2- and 5-year DFS owing to the inclusion of limited studies, a trend of favoring $\mathrm{LH}$ was observed. We speculated that the better prognosis of LH patients might lie in the less compression during laparoscopic manipulation, which prevented tumor cell metastasis. In addition, the minimally invasive approach resulted in faster recovery of the immune and nutritional status, which may also contribute to better prognosis. 
TABLE 3 | Subgroup analysis of outcomes based on the surgical extents.

\begin{tabular}{|c|c|c|c|c|c|c|}
\hline Outcomes & Included studies & Sample size & 12 & Pooled mode & Pooled effect & $P$ value \\
\hline \multicolumn{7}{|l|}{ Operation time } \\
\hline All & 16 & 1975 & $93.7 \%$ & Random & WMD:19.33(-1.67,40.34) & 0.07 \\
\hline Minor resection & 9 & 1351 & $93.9 \%$ & Random & WMD:14.80(-11.24,40.85) & 0.27 \\
\hline Major resection & 5 & 448 & $84.7 \%$ & Random & WMD:47.24(5.52,89.00) & 0.03 \\
\hline \multicolumn{7}{|l|}{ Blood loss } \\
\hline All & 15 & 1853 & $57.0 \%$ & Random & WMD:-69.16(-101.72,-36.61) & $<0.01$ \\
\hline Minor resection & 9 & 1351 & $34.3 \%$ & Fixed & WMD:-84.75(-112.22,-57.29) & $<0.01$ \\
\hline Major resection & 4 & 326 & $0.0 \%$ & Fixed & WMD:-1.97(-65.34,61.40) & 0.95 \\
\hline \multicolumn{7}{|l|}{ Transfusion } \\
\hline All & 10 & 1381 & $7.3 \%$ & Fixed & OR:0.63(0.40,1.00) & 0.05 \\
\hline Minor resection & 4 & 823 & $0.0 \%$ & Fixed & OR:0.52(0.27.1.02) & 0.06 \\
\hline Major resection & 4 & 382 & $0.0 \%$ & Fixed & OR:0.71(0.34,1.49) & 0.36 \\
\hline \multicolumn{7}{|l|}{$\mathrm{LOH}$} \\
\hline All & 16 & 1975 & $69.4 \%$ & Random & WMD:-2.65(-3.41,-1.89) & $<0.01$ \\
\hline Minor resection & 9 & 1351 & $70.8 \%$ & Random & WMD:-2.45(-3.33,-1.57) & $<0.01$ \\
\hline Major resection & 5 & 448 & $4.6 \%$ & Random & WMD:-2.99(-4.11,-1.86) & $<0.01$ \\
\hline \multicolumn{7}{|l|}{ Overall complication } \\
\hline All & 15 & 1859 & $0.0 \%$ & Fixed & OR:0.57(0.46,0.71) & $<0.01$ \\
\hline Minor resection & 9 & 1351 & $0.0 \%$ & Fixed & OR:0.61(0.48,0.78) & $<0.01$ \\
\hline Major resection & 5 & 448 & $0.0 \%$ & Fixed & OR:0.47(0.30,0.75) & $<0.01$ \\
\hline \multicolumn{7}{|l|}{ Minor complication } \\
\hline All & 8 & 1295 & $0.0 \%$ & Fixed & OR:0.70(0.53,0.94) & 0.02 \\
\hline Minor resection & 6 & 1099 & $0.0 \%$ & Fixed & OR:0.76(0.55,1.03) & 0.08 \\
\hline Major resection & 2 & 196 & $0.0 \%$ & Fixed & OR:0.41(0.18,0.95) & 0.04 \\
\hline \multicolumn{7}{|l|}{ Major complication } \\
\hline All & 10 & 1467 & $0.0 \%$ & Fixed & OR:0.52(0.33,0.82) & $<0.01$ \\
\hline Minor resection & 7 & 1215 & $0.0 \%$ & Fixed & OR:0.57(0.34,0.94) & 0.03 \\
\hline Major resection & 2 & 196 & $0.0 \%$ & Fixed & OR:0.54(0.19,1.56) & 0.26 \\
\hline \multicolumn{7}{|l|}{ Mortality } \\
\hline All & 10 & 1425 & $0.0 \%$ & Fixed & OR:0.27(0.11,0.66) & $<0.01$ \\
\hline Minor resection & 6 & 1063 & $0.0 \%$ & Fixed & OR:0.26(0.08,0.83) & 0.02 \\
\hline Major resection & 3 & 306 & $0.0 \%$ & Fixed & OR:0.34(0.06,1.94) & 0.22 \\
\hline \multicolumn{7}{|l|}{ POLF } \\
\hline All & 10 & 1352 & $0.0 \%$ & Fixed & OR:0.60(0.38,0.95) & 0.03 \\
\hline Minor resection & 5 & 914 & $0.0 \%$ & Fixed & OR:0.63(0.33,1.21) & 0.17 \\
\hline Major resection & 4 & 382 & $0.0 \%$ & Fixed & OR:0.60(0.31,1.17) & 0.14 \\
\hline \multicolumn{7}{|l|}{ Ascites } \\
\hline All & 11 & 971 & $0.00 \%$ & Fixed & OR:0.44(0.28,0.72) & $<0.01$ \\
\hline Minor resection & 7 & 663 & $0.00 \%$ & Fixed & OR:0.48(0.27,0.86) & 0.01 \\
\hline Major resection & 3 & 252 & $0.00 \%$ & Fixed & OR:0.43(0.18,1.02) & 0.05 \\
\hline \multicolumn{7}{|l|}{ 1-year OS } \\
\hline All & 11 & 1367 & $32.90 \%$ & Fixed & HR:0.48(0.31,0.73) & $<0.01$ \\
\hline Minor resection & 7 & 985 & $0 \%$ & Fixed & HR:0.42(0.26,0.68) & $<0.01$ \\
\hline Major resection & 4 & 382 & $36.4 \%$ & Fixed & HR:0.72(0.30,1.74) & 0.46 \\
\hline \multicolumn{7}{|l|}{ 2-year OS } \\
\hline All & 12 & 1433 & $0.00 \%$ & Fixed & HR:0.61(0.45,0.83) & $<0.01$ \\
\hline Minor resection & 7 & 985 & $0 \%$ & Fixed & HR:0.59(0.42,0.85) & $<0.01$ \\
\hline Major resection & 5 & 448 & $31.7 \%$ & Fixed & HR:0.66(0.37,1.17) & 0.16 \\
\hline \multicolumn{7}{|l|}{5 -year OS } \\
\hline All & 7 & 1127 & $31.70 \%$ & Fixed & HR:0.67(0.53,0.85) & $<0.01$ \\
\hline Minor resection & 5 & 885 & $35 \%$ & Fixed & HR:0.69(0.53,0.90) & $<0.01$ \\
\hline Major resection & 2 & 242 & $55.8 \%$ & Random & HR:0.57(0.26,1.30) & 0.18 \\
\hline \multicolumn{7}{|l|}{ 1-year DFS } \\
\hline All & 11 & 1387 & $59.70 \%$ & Random & HR:0.73(0.52,1.04) & 0.08 \\
\hline Minor resection & 6 & 939 & $67.10 \%$ & Random & HR:0.63(0.41,0.96) & 0.03 \\
\hline Major resection & 5 & 448 & $22.3 \%$ & Fixed & HR:1.03(0.69,1.56) & 0.88 \\
\hline 2-year DFS & & & & & & \\
\hline All & 11 & 1387 & $0 \%$ & Fixed & HR:0.86(0.73,1.02) & 0.08 \\
\hline Minor resection & 6 & 939 & $0 \%$ & Fixed & HR:0.87(0.72,1.05) & 0.15 \\
\hline Major resection & 5 & 448 & $0 \%$ & Fixed & HR:0.83(0.59,1.17) & 0.29 \\
\hline 5-year DFS & & & & & & \\
\hline All & 6 & 781 & $23.80 \%$ & Fixed & HR:0.90(0.75,1.07) & 0.23 \\
\hline
\end{tabular}


TABLE 3 | Continued

\begin{tabular}{lccccc}
\hline Outcomes & Included studies & Sample size & I2 & Pooled mode & Pooled effect \\
\hline Minor resection & 4 & 735 & $0 \%$ & Fixed & HR:0.87(0.71,1.06) \\
Major resection & 2 & 242 & $81.9 \%$ & Random & HR:0.95(0.37,2.44) \\
\hline
\end{tabular}

LOH length of hospitalization, Cl confidence interval, WMD weighted mean difference, OR odds ratio, POLF postoperative liver failure, HR hazard ratio, OS overall survival, DFS disease-free survival disease-free survival.

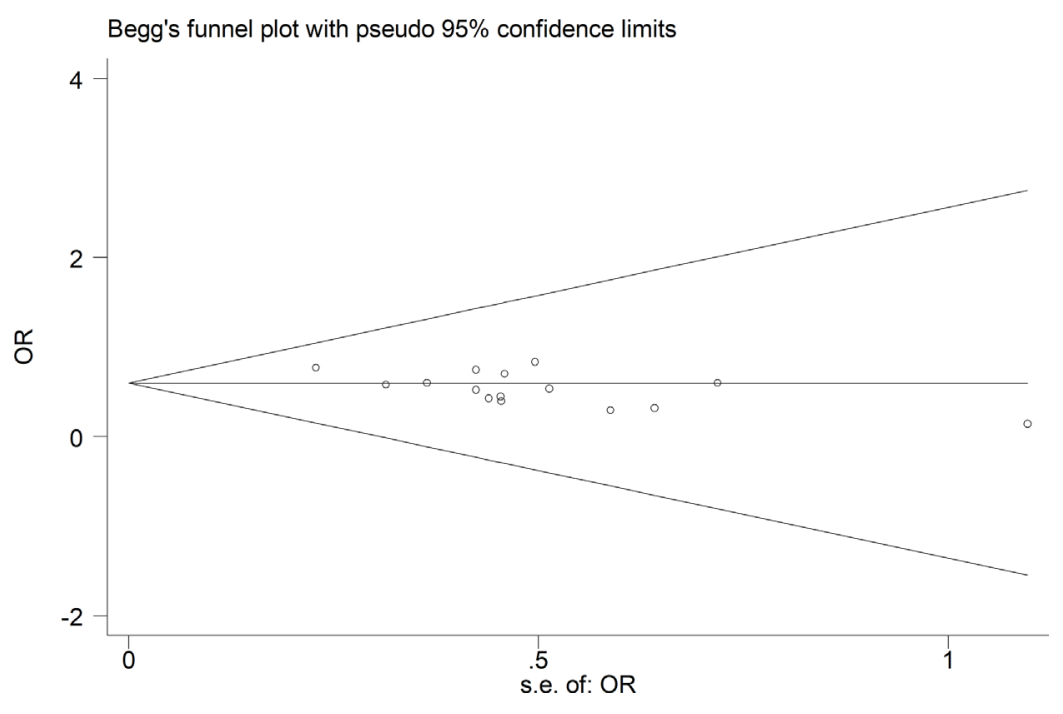

FIGURE 6 | Funnel plots of postoperative complication.

TABLE 4 | Summary of outcomes reported by previous meta-analysis and present meta-analysis.

\begin{tabular}{|c|c|c|c|c|c|c|c|c|c|c|c|c|c|}
\hline Study & $\begin{array}{l}\text { Latest } \\
\text { literature } \\
\text { search }\end{array}$ & $\begin{array}{l}\text { Included } \\
\text { studies }\end{array}$ & $\begin{array}{c}\text { Study } \\
\text { characteristics }\end{array}$ & $\begin{array}{l}\text { Operation } \\
\text { time }\end{array}$ & $\begin{array}{c}\text { Blood } \\
\text { loss }\end{array}$ & $\begin{array}{l}\text { Blood } \\
\text { transfusion }\end{array}$ & $\begin{array}{l}\text { postoperative } \\
\text { morbidity }\end{array}$ & $\begin{array}{l}\text { postoperative } \\
\text { mortality }\end{array}$ & LOH & $\begin{array}{l}1- \\
\text { year } \\
\text { OS }\end{array}$ & $\begin{array}{l}5- \\
\text { year } \\
\text { OS }\end{array}$ & $\begin{array}{l}\text { 1-year } \\
\text { DFS }\end{array}$ & $\begin{array}{c}\text { 5-year } \\
\text { DFS }\end{array}$ \\
\hline $\begin{array}{l}\text { Chen } \\
\text { et al. }\end{array}$ & 2015.3 & 7 & $R \& R M$ & E & FLH & FLH & FLH & E & FLH & E & FLH & E & $E$ \\
\hline $\begin{array}{l}\text { Goh } \\
\text { et al. }\end{array}$ & 2016.11 & 5 & R\&RM & NA & NA & NA & NA & NA & NA & FLH & FLH & FLH & $E$ \\
\hline
\end{tabular}

LOH length of hospitalization, OS overall survival, DFS disease-free survival, R retrospective study, RM retrospective matched study, RCT randomized clinical trial, E equivalent, FLH favors laparoscopic hepatectomy, NA not available.

Unlike previous meta-analyses on this issue, the present study performed subgroup analysis based on the surgical extent, which was necessary to eliminate such heterogeneity among the studies. The present study found that the results of subgroup analysis based on minor resection were in line with the results of the overall analysis, however, the results of subgroup analysis based on major resection should be cautiously interpreted, although only three studies were included. As expected, LMH was a potential alternative to its open counterpart, and it maintained the advantage of shorter $\mathrm{LOH}$ and fewer postoperative complications as in laparoscopic minor hepatectomy. However, LMH had a longer operation time than the open approach, suggesting that this procedure is technically demanding. Notably, Komatsu et al. reported a conversion rate of $34.21 \%$ in the $\mathrm{LMH}$ group, reflecting the steep learning curve of LMH in the setting of HCC with cirrhosis. Comprehensive liver function assessment and a good understanding of the liver anatomy, as well as ample surgical expertise, are the most important factors for successful LMH. Emerging evidence proving the value of $\mathrm{LMH}$ may lead to the expansion of the indication of LH to HCC patients with cirrhosis.

Our review has notable strengths as follows: (i) all included studies were case-matched studies, which balanced the baseline 
characteristics and reduced the selection bias, (ii) more detailed data than in other meta-analyses were extracted and analyzed, and (iii) "HR" instead of "OR" was applied in analyzing time-toevent data, such OS and DFS. Nevertheless, the present metaanalysis also had several limitations. First, most of the included studies were retrospective studies which adversely affected the overall quality of the evidence. Although the baseline characteristics of confounding factors were balanced in all included retrospective studies, the allocation of patients was rarely described in the included studies, which inevitably resulted in selection bias. Second, none of the included studies prospectively has calculated the sufficient sample size to identify differences between $\mathrm{OH}$ and LH. Several studies with small sample sizes presented the initial experience of surgeons in performing LH, although those surgeons might have a high level of expertise in $\mathrm{OH}$. The lack of sufficient sample size and quality control of the surgical techniques might also bring bias. Third, LH is considered as an emerging and potentially better alternative to $\mathrm{OH}$. It can't be guaranteed that all results, including $\mathrm{LH}$ with poor outcomes, were reported, and no mandatory registration is required in observational studies, which can be a source of publication bias.

\section{CONCLUSION}

In summary, this systematic review and meta-analysis comparing $\mathrm{LH}$ and $\mathrm{OH}$ demonstrated that $\mathrm{LH}$ can be safely performed in selected HCC patients with cirrhosis. LH offers favorable short-term outcomes and long-term oncological outcomes in minor liver resections. Although LMH seems to offer some advantages over the open approach, concerns about surgical and oncological safety remain. More evidence on LMH is warranted before expanding its indication to patients with cirrhosis.

\section{REFERENCES}

1. Njei B, Rotman Y, Ditah I, Lim JK. Emerging trends in hepatocellular carcinoma incidence and mortality. Hepatol (Baltimore Md) (2015) 61 (1):191-9. doi: 10.1002/hep.27388

2. El-Serag HB. Hepatocellular carcinoma. New Engl J Med (2011) 365 (12):1118-27. doi: 10.1056/NEJMra1001683

3. Reich H, McGlynn F, DeCaprio J, Budin R. Laparoscopic excision of benign liver lesions. Obstetrics Gynecol (1991) 78(5 Pt 2):956-8.

4. Katkhouda N, Fabiani P, Benizri E, Mouiel J. Laser resection of a liver hydatid cyst under videolaparoscopy. Br J Surg (1992) 79(6):560-1. doi: 10.1002/ bjs. 1800790628

5. Buell JF, Cherqui D, Geller DA, O'Rourke N, Iannitti D, Dagher I, et al. The international position on laparoscopic liver surgery: The Louisville Statement, 2008. Ann Surg (2009) 250(5):825-30. doi: 10.1097/sla.0b013e3181b3b2d8

6. Takahara T, Wakabayashi G, Beppu T, Aihara A, Hasegawa K, Gotohda N, et al. Long-term and perioperative outcomes of laparoscopic versus open liver resection for hepatocellular carcinoma with propensity score matching: a multi-institutional Japanese study. J Hepato-biliary-pancreatic Sci (2015) 22 (10):721-7. doi: 10.1002/jhbp.276

7. Neeff H, Mariaskin D, Spangenberg HC, Hopt UT, Makowiec F. Perioperative mortality after non-hepatic general surgery in patients with liver cirrhosis: an analysis of 138 operations in the 2000s using Child and MELD scores.

\section{DATA AVAILABILITY STATEMENT}

The raw data supporting the conclusions of this article will be made available by the authors, without undue reservation.

\section{ETHICS STATEMENT}

This research was an analysis of published data and did not require informed consent. Ethics approval and consent to participate were not applicable in this research.

\section{AUTHOR CONTRIBUTIONS}

Conception and design: X-JC and YP. Administrative support: $\mathrm{X}-\mathrm{JC}$. Provision of study material or patients: YP, KC, and S-JX. Collection and assembly of data: KC, S-JX, and J-QC. Data analysis and interpretation: YP. Manuscript writing: all authors. All authors contributed to the article and approved the submitted version.

\section{FUNDING}

This work was supported by the National Natural Science Foundation of China under Grant No. 81701911

\section{SUPPLEMENTARY MATERIAL}

The Supplementary Material for this article can be found online at: https://www.frontiersin.org/articles/10.3389/fonc.2021. 652272/full\#supplementary-material

J Gastrointestinal Surg: Off J Soc Surg Alimentary Tract (2011) 15(1):1-11. doi: 10.1007/s11605-010-1366-9

8. Tarantino G, Magistri P, Serra V, Berardi G, Assirati G, Ballarin R, et al. Laparoscopic Liver Resection of Right Posterior Segments for Hepatocellular Carcinoma on Cirrhosis. J Laparoendoscopic Adv Surg Techniq Part A (2017) 27(6):559-63. doi: 10.1089/lap.2016.0506

9. Siniscalchi A, Ercolani G, Tarozzi G, Gamberini L, Cipolat L, Pinna AD, et al. Laparoscopic versus Open Liver Resection: Differences in Intraoperative and Early Postoperative Outcome among Cirrhotic Patients with Hepatocellular Carcinoma-A Retrospective Observational Study. HPB Surg: World J Hepatic Pancreatic Biliary Surg (2014) 2014:871251. doi: 10.1155/2014/871251

10. Worhunsky DJ, Dua MM, Tran TB, Siu B, Poultsides GA, Norton JA, et al. Laparoscopic hepatectomy in cirrhotics: safe if you adjust technique. Surg Endoscopy (2016) 30(10):4307-14. doi: 10.1007/s00464-016-4748-6

11. Cannon RM, Saggi B, Buell JF. Evaluation of a laparoscopic liver resection in the setting of cirrhosis. HPB: Off J Int Hepato Pancreato Biliary Assoc (2014) 16(2):164-9. doi: 10.1111/hpb.12098

12. Twaij A, Pucher PH, Sodergren MH, Gall T, Darzi A, Jiao LR. Laparoscopic vs open approach to resection of hepatocellular carcinoma in patients with known cirrhosis: systematic review and meta-analysis. World J Gastroenterol (2014) 20(25):8274-81. doi: 10.3748/wjg.v20.i25.8274

13. Chen J, Bai T, Zhang Y, Xie ZB, Wang XB, Wu FX, et al. The safety and efficacy of laparoscopic and open hepatectomy in hepatocellular carcinoma 
patients with liver cirrhosis: a systematic review. Int J Clin Exp Med (2015) 8 (11):20679-89.

14. El-Gendi A, El-Shafei M, El-Gendi S, Shawky A. Laparoscopic Versus Open Hepatic Resection for Solitary Hepatocellular Carcinoma Less Than $5 \mathrm{~cm}$ in Cirrhotic Patients: A Randomized Controlled Study. J Laparoendoscopic Adv Surg Techniq Part A (2018) 28(3):302-10. doi: 10.1089/lap.2017.0518

15. Di Sandro S, Bagnardi V, Najjar M, Buscemi V, Lauterio A, De Carlis R, et al. Minor laparoscopic liver resection for Hepatocellular Carcinoma is safer than minor open resection, especially for less compensated cirrhotic patients: Propensity score analysis. Surg Oncol (2018) 27(4):722-9. doi: 10.1016/ j.suronc.2018.10.001

16. Kim WJ, Kim KH, Kim SH, Kang WH, Lee SG. Laparoscopic Versus Open Liver Resection for Centrally Located Hepatocellular Carcinoma in Patients With Cirrhosis: A Propensity Score-matching Analysis. Surg Laparoscopy Endoscopy Percutaneous Techniq (2018) 28(6):394-400. doi: 10.1097/ sle.0000000000000569

17. Yoon YI, Kim KH, Kang SH, Kim WJ, Shin MH, Lee SK, et al. Pure Laparoscopic Versus Open Right Hepatectomy for Hepatocellular Carcinoma in Patients With Cirrhosis: A Propensity Score Matched Analysis. Ann Surg (2017) 265(5):856-63. doi: 10.1097/sla.0000000000002072

18. Xu HW, Liu F, Li HY, Wei YG, Li B. Outcomes following laparoscopic versus open major hepatectomy for hepatocellular carcinoma in patients with cirrhosis: a propensity score-matched analysis. Surg Endoscopy (2018) 32 (2):712-9. doi: 10.1007/s00464-017-5727-2

19. Moher D, Liberati A, Tetzlaff J, Altman DG. Preferred reporting items for systematic reviews and meta-analyses: the PRISMA statement. J Clin Epidemiol (2009) 62(10):1006-12. doi: 10.1016/j.jclinepi.2009.06.005

20. Strasberg SM. Nomenclature of hepatic anatomy and resections: a review of the Brisbane 2000 system. J Hepato-biliary-pancreatic Surg (2005) 12(5):3515. doi: 10.1007/s00534-005-0999-7

21. Hasegawa Y, Nitta H, Takahara T, Katagiri H, Baba S, Takeda D, et al. Safely extending the indications of laparoscopic liver resection: When should we start laparoscopic major hepatectomy? Surg Endoscopy (2017) 31(1):309-16. doi: 10.1007/s00464-016-4973-z

22. Goh BKP, Teo JY, Lee SY, Kam JH, Cheow PC, Jeyaraj P, et al. Critical appraisal of the impact of individual surgeon experience on the outcomes of laparoscopic liver resection in the modern era: collective experience of multiple surgeons at a single institution with 324 consecutive cases. Surg Endoscopy (2018) 32(4):1802-11. doi: 10.1007/s00464-017-5864-7

23. Dindo D, Demartines N, Clavien PA. Classification of surgical complications: a new proposal with evaluation in a cohort of 6336 patients and results of a survey. Ann Surg (2004) 240(2):205-13. doi: 10.1097/01.sla.0000133083.54934.ae

24. Tierney JF, Stewart LA, Ghersi D, Burdett S, Sydes MR. Practical methods for incorporating summary time-to-event data into meta-analysis. Trials (2007) 8:16. doi: $10.1186 / 1745-6215-8-16$

25. Hozo SP, Djulbegovic B, Hozo I. Estimating the mean and variance from the median, range, and the size of a sample. BMC Med Res Method (2005) 5:13. doi: 10.1186/1471-2288-5-13

26. Higgins JP, Thompson SG, Deeks JJ, Altman DG. Measuring inconsistency in meta-analyses. BMJ (Clin Res ed) (7414) (2003) 327:557-60. doi: 10.1136/ bmj.327.7414.557

27. Mantel N, Haenszel W. Statistical aspects of the analysis of data from retrospective studies of disease. J Natl Cancer Institute (1959) 22(4):719-48.

28. DerSimonian R, Laird N. Meta-analysis in clinical trials. Controlled Clin Trials (1986) 7(3):177-88. doi: 10.1016/0197-2456(86)90046-2

29. Yamashita Y, Ikeda T, Kurihara T, Yoshida Y, Takeishi K, Itoh S, et al. Longterm favorable surgical results of laparoscopic hepatic resection for hepatocellular carcinoma in patients with cirrhosis: a single-center experience over a 10-year period. J Am Coll Surgeons (2014) 219(6):111723. doi: 10.1016/j.jamcollsurg.2014.09.003

30. Cheung TT, Ma KW, She WH, Dai WC, Tsang SHY, Chan ACY, et al. Pure laparoscopic hepatectomy with augmented reality-assisted indocyanine green fluorescence versus open hepatectomy for hepatocellular carcinoma with liver cirrhosis: A propensity analysis at a single center. Asian J Endoscopic Surg (2018) 11(2):104-11. doi: 10.1111/ases.12492

31. Cheung TT, Poon RT, Yuen WK, Chok KS, Jenkins CR, Chan SC, et al. Longterm survival analysis of pure laparoscopic versus open hepatectomy for hepatocellular carcinoma in patients with cirrhosis: a single-center experience. Ann Surg (2013) 257(3):506-11. doi: 10.1097/SLA.0b013e31827b947a

32. Vega EA, Kutlu OC, Joechle K, De La Cruz N, Ko D, Conrad C. Preoperative Prognosticators of Safe Laparoscopic Hepatocellular Carcinoma Resection in Advanced Cirrhosis: a Propensity Score Matching Population-Based Analysis of 1799 Western Patients. J Gastrointestinal Surg: Off J Soc Surg Alimentary Tract (2019) 23(6):1157-65. doi: 10.1007/s11605-019-04139-7

33. Jin H, Yin Z, Zhou Y, Ma T, Jian Z. Safety and Feasibility of a LaparoscopyAssisted Non-Anatomic Resection Technique for Hepatocellular Carcinoma Located at Right Posterior Segments in Cirrhotic Patients: A Case-Controlled Study with Propensity Score Matching. Digestive Surg (2018) 35(5):411-8. doi: $10.1159 / 000480359$

34. Lee KF, Chong CN, Wong J, Cheung YS, Wong J, Lai P. Long-term results of laparoscopic hepatectomy versus open hepatectomy for hepatocellular carcinoma: a case-matched analysis. World J Surg (2011) 35(10):2268-74. doi: 10.1007/s00268-011-1212-6

35. Sposito C, Battiston C, Facciorusso A, Mazzola M, Muscarà C, Scotti M, et al. Propensity score analysis of outcomes following laparoscopic or open liver resection for hepatocellular carcinoma. Br J Surg (2016) 103(7):871-80. doi: $10.1002 / b j s .10137$

36. Tanaka S, Takemura S, Shinkawa H, Nishioka T, Hamano G, Kinoshita M, et al. Outcomes of Pure Laparoscopic versus Open Hepatic Resection for Hepatocellular Carcinoma in Cirrhotic Patients: A Case-Control Study with Propensity Score Matching. Eur Surg Res Europaische Chirurgische Forschung Recherches Chirurgicales Europeennes (2015) 55(4):291-301. doi: 10.1159/ 000439274

37. Wu X, Huang Z, Lau WY, Li W, Lin P, Zhang L, et al. Perioperative and longterm outcomes of laparoscopic versus open liver resection for hepatocellular carcinoma with well-preserved liver function and cirrhotic background: a propensity score matching study. Surg Endoscopy (2019) 33(1):206-15. doi: 10.1007/s00464-018-6296-8

38. Kanazawa A, Tsukamoto T, Shimizu S, Kodai S, Yamazoe S, Yamamoto S, et al. Impact of laparoscopic liver resection for hepatocellular carcinoma with F4-liver cirrhosis. Surg Endoscopy (2013) 27(7):2592-7. doi: 10.1007/s00464-013-2795-9

39. Belli G, Fantini C, D’Agostino A, Cioffi L, Langella S, Russolillo N, et al. Laparoscopic versus open liver resection for hepatocellular carcinoma in patients with histologically proven cirrhosis: short- and middle-term results. Surg Endoscopy (2007) 21(11):2004-11. doi: 10.1007/s00464-007-9503-6

40. Komatsu S, Brustia R, Goumard C, Perdigao F, Soubrane O, Scatton O. Laparoscopic versus open major hepatectomy for hepatocellular carcinoma: a matched pair analysis. Surg Endoscopy (2016) 30(5):1965-74. doi: 10.1007/ s00464-015-4422-4

41. Memeo R, de'Angelis N, Compagnon P, Salloum C, Cherqui D, Laurent A, et al. Laparoscopic vs. open liver resection for hepatocellular carcinoma of cirrhotic liver: a case-control study. World J Surg (2014) 38(11):2919-26. doi: 10.1007/s00268-014-2659-z

42. Truant S, Bouras AF, Hebbar M, Boleslawski E, Fromont G, Dharancy S, et al. Laparoscopic resection vs. open liver resection for peripheral hepatocellular carcinoma in patients with chronic liver disease: a case-matched study. Surg Endoscopy (2011) 25(11):3668-77. doi: 10.1007/s00464-011-1775-1

43. Cheung TT, Dai WC, Tsang SH, Chan AC, Chok KS, Chan SC, et al. Pure Laparoscopic Hepatectomy Versus Open Hepatectomy for Hepatocellular Carcinoma in 110 Patients With Liver Cirrhosis: A Propensity Analysis at a Single Center. Ann Surg (2016) 264(4):612-20. doi: 10.1097/sla.0000000 000001848

44. Jiang X, Liu L, Zhang Q, Jiang Y, Huang J, Zhou H, et al. Laparoscopic versus open hepatectomy for hepatocellular carcinoma: long-term outcomes. J BUON: Off J Balkan Union Oncol (2016) 21(1):135-41.

45. Delvecchio A, Conticchio M, Ratti F, Gelli M, Anelli FM, Laurent A, et al. Laparoscopic major hepatectomy for hepatocellular carcinoma in elderly patients: a multicentric propensity score-based analysis. Surg Endoscopy (2020). doi: 10.1007/s00464-020-07843-7

46. Fu XT, Tang Z, Chen JF, Shi YH, Liu WR, Gao Q, et al. Laparoscopic hepatectomy enhances recovery for small hepatocellular carcinoma with liver cirrhosis by postoperative inflammatory response attenuation: a propensity score matching analysis with a conventional open approach. Surg Endoscopy (2021) 35(2):910-20. doi: 10.1007/s00464-020-07710-5 
47. Inoue $\mathrm{Y}$, Yokohama $\mathrm{K}$, Ohama H, Tsuchimoto $\mathrm{Y}$, Terazawa $\mathrm{T}$, Asai A, et al. Efficacy and safety of laparoscopic hepatectomy for hepatocellular carcinoma comorbid with cirrhosis. Przeglad Gastroenterol (2020) 15(3):225-33. doi: 10.5114/pg.2020.99039

48. Cheung TT, Ma KW, She WH, Dai WC, Tsang SHY, Chan ACY, et al. Pure laparoscopic versus open major hepatectomy for hepatocellular carcinoma with liver F4 cirrhosis without routine Pringle maneuver - A propensity analysis in a single center. Surg Oncol (2020) 35:315-20. doi: 10.1016/j.suronc.2020.09.012

49. Hobeika C, Nault JC, Barbier L, Schwarz L, Lim C, Laurent A, et al. Influence of surgical approach and quality of resection on the probability of cure for early-stage HCC occurring in cirrhosis. JHEP Rep: Innovation Hepatol (2020) 2(6):100153. doi: 10.1016/j.jhepr.2020.100153

50. Yamamoto M, Kobayashi T, Oshita A, Abe T, Kohashi T, Onoe T, et al. Laparoscopic versus open limited liver resection for hepatocellular carcinoma with liver cirrhosis: a propensity score matching study with the Hiroshima Surgical study group of Clinical Oncology (HiSCO). Surg Endoscopy (2020) 34 (11):5055-61. doi: 10.1007/s00464-019-07302-y

51. Goh EL, Chidambaram S, Ma S. Laparoscopic vs open hepatectomy for hepatocellular carcinoma in patients with cirrhosis: A meta-analysis of the long-term survival outcomes. Int J Surg (London England) (2018) 50:35-42. doi: 10.1016/j.ijsu.2017.12.021

52. Goh BKP, Lee SY, Teo JY, Kam JH, Jeyaraj PR, Cheow PC, et al. Changing trends and outcomes associated with the adoption of minimally invasive hepatectomy: a contemporary single-institution experience with 400 consecutive resections. Surg Endoscopy (2018) 32(11):4658-65. doi: 10.1007/ s00464-018-6310-1

Conflict of Interest: The authors declare that the research was conducted in the absence of any commercial or financial relationships that could be construed as a potential conflict of interest.

Copyright (C) 2021 Pan, Xia, Cai, Chen and Cai. This is an open-access article distributed under the terms of the Creative Commons Attribution License (CC BY). The use, distribution or reproduction in other forums is permitted, provided the original author(s) and the copyright owner(s) are credited and that the original publication in this journal is cited, in accordance with accepted academic practice. No use, distribution or reproduction is permitted which does not comply with these terms. 